\title{
MOLECULAR NEUROGENETICS OF MITOCHONDRIAL DISEASES
}

E. Cardaioli, P. Da Pozzo, G.N. Gallus, S. Bianchi, C. D’Eramo, E. Malfatti e A. Federico.

\section{Department of Neurological and Behavioural Sciences University of Siena}

Mitochondrial diseases are an expanding group of clinically heterogeneous disorders associated with mitochondrial DNA (mtDNA) mutations or nuclear gene defects. Whatever the mechanism, the final common step in mitochondrial disorders is a defect of energy production resulting from respiratory chain impairment. The complexity of the biochemical and genetic features of the respiratory chain accounts for the extraordinarily wide range of clinical presentations of mitochondrial disorders. In general, organs with high aerobic demand, such as skeletal muscle, brain and heart, are the most affected. However, virtually any organ or tissue in the body may be affected and the disorders can be multisystemic (mitochondrial encephalomyopathies) or confined to a single tissue. Moreover, mitochondrial diseases can be sporadic or transmitted by mendelian (nuclear genes) or maternal inheritance (mutations in mtDNA). Precise diagnosis is often a challenge; we go through the traditional steps of the diagnostic process, starting with study of inheritance in the family, clinical manifestations in the individual, electrophysiology and imaging techniques at organ level, down to biochemistry, pathology and molecular genetics at tissue, cell and DNA level, respectively. In fact the ultimate goal is to reach, whenever possible, a definitive molecular diagnosis, which can permit rational therapeutic approach and a genetic counseling.

\section{INTRODUCTION}

Mitochondrial encephalomyopathies are an expanding group of clinically heterogeneous disorders associated with mitochondrial DNA (mtDNA) mutations or nuclear gene defects $(1,2,3)$.

Whatever the mechanism, the final common step in mitochondrial encephalomyopathies is a defect of energy production resulting from respiratory chain impairment. The complexity of the biochemical and genetic features of the respiratory chain accounts for the extraordinarily wide range of clinical presentations of mitochondrial disor-

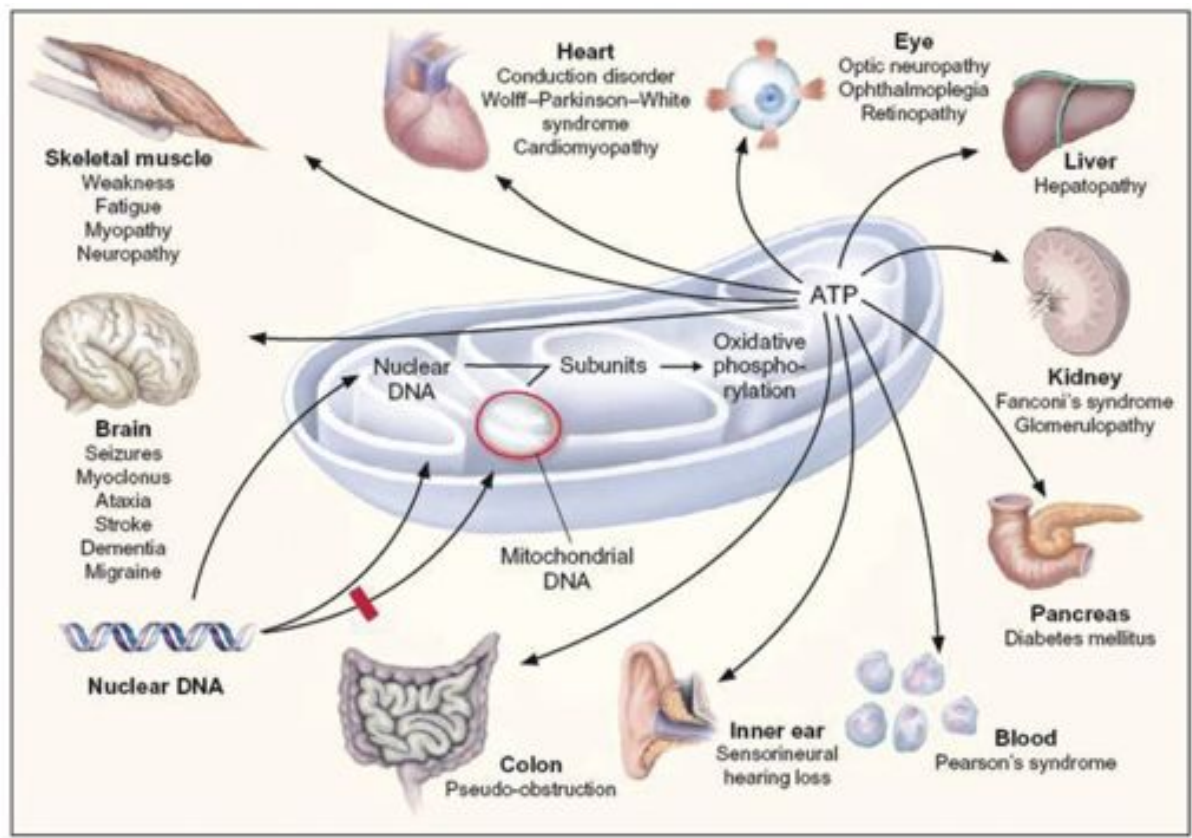
ders. In general, organs with high aerobic demand, such as skeletal muscle, brain and heart, are the most affected. However, virtually any organ or tissue in the body may be affected (4) (Fig.1).

Phenotypes of mitochondrial diseases include sensorineural hearing loss, myoclonic seizures, ataxia, diabetes, muscle weakness, loss of vision, cardiomyopathy, short stature, ophthalmoplegia, stroke and headaches. In general, postmitotic and metabolically active cells are usually more affected in mtDNA disease, and examples include cochlear hair cells, myocytes, neurons and pancreatic islet cells.

\section{Classification OF MitochondRIAL DiseASES}

Identification of mutations in mtDNA and nuclear genes related to oxidative phosphorylation (OXPHOS) has provided the basis for the current classification of mitochondrial disorders.

The first group of illnesses is characterized by mutations in mtDNA, that can be either sporadic or maternally transmitted. A second group of disorders is
Fig.1: Any organ or tissue in the body can be affected in mitochondrial encephalomyopathies. Source: N Engl J Med. 1995; 333 (10):638-44
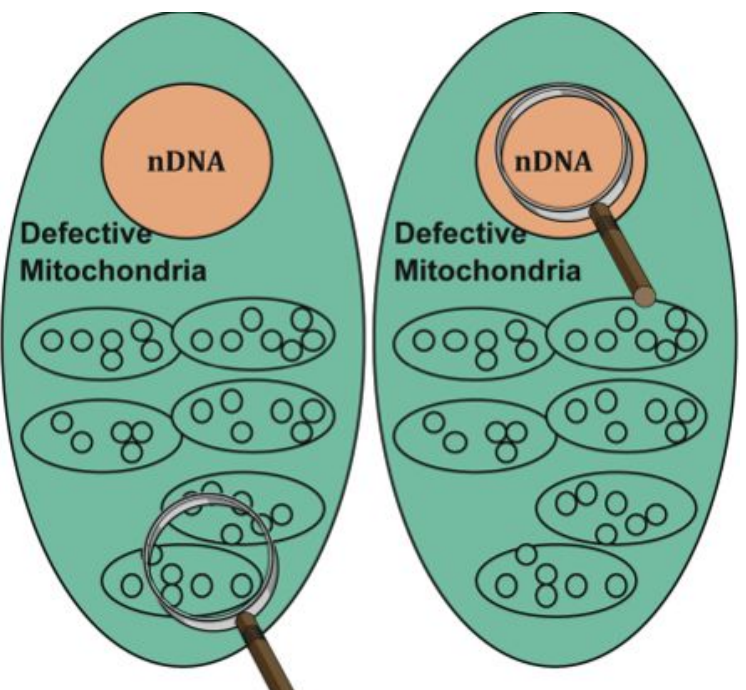

Fig.2: The mitochondrial defect may be due to mutations in mtDNA or in nuclear genes. 
caused by mutations in nuclear genes that make up or control OXPHOS (Fig.2). Because many OXPHOS-related nuclear genes are still unkown in humans, several of these illnesses are classified only on the basis of biochemical alterations, revealed by analysis of affected tissue (especially skeletal muscle).

\section{MitOCHONDRIAL GENETICS}

Individual cells contain many mitochondria and each mitochondrion contains 2-10 copies of the mtDNA molecule. Human mtDNA is a circular, doublestranded molecule of 16569 base pairs; it contains 37 genes, including 13 protein-encoding genes, 22 transfer RNA genes and 2 ribosomal RNA genes (Fig.3). All 13 protein-encoding genes are components of the mitochondrial respiratory chain, which is located in the inner membrane of mitochondria (Fig.4).

Because of its cytoplasmic location, its high copy number and the lack of repair mechanisms, the mtDNA has unique genetics:

1) mtDNA is maternally inherited (5). Therefore, a mother carrying an mtDNA mutation is expected to pass it on to all her children, but only her daughters will transmit it to their progeny (Fig. 5).

2) mtDNA has a very high mutation rate. Mutations in mtDNA are 5-10 times more frequent than those in nuclear genes. This means that the mtDNA sequence of any person differs from that of any other person in the world by an average of 25 base pair substitutions (6).

3 ) When a new mutation occurs in an mtDNA molecule, it creates a mixed intracellular population of mutant and normal mtDNAs, known as heteroplasmy (when the mtDNA molecules are all identical, we use the term "homoplasmy"). When a heteroplasmic cell divides, the mutant and normal mtDNAs are randomly distributed into the daughter cells. This replicative segregation process can therefore generate all possible percentages of mu-
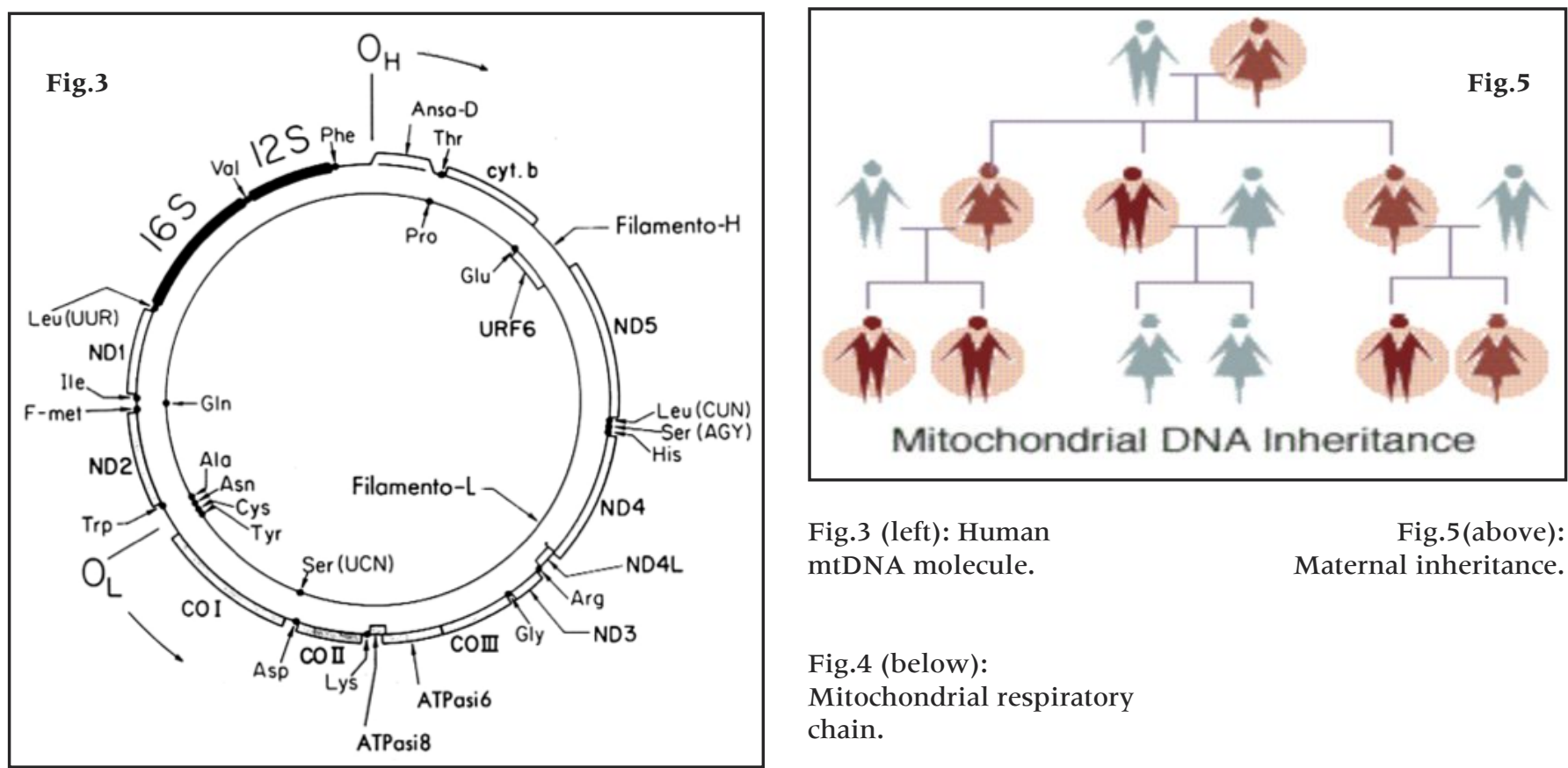

Fig.3 (left): Human mtDNA molecule.

Fig.4 (below):

Mitochondrial respiratory chain.

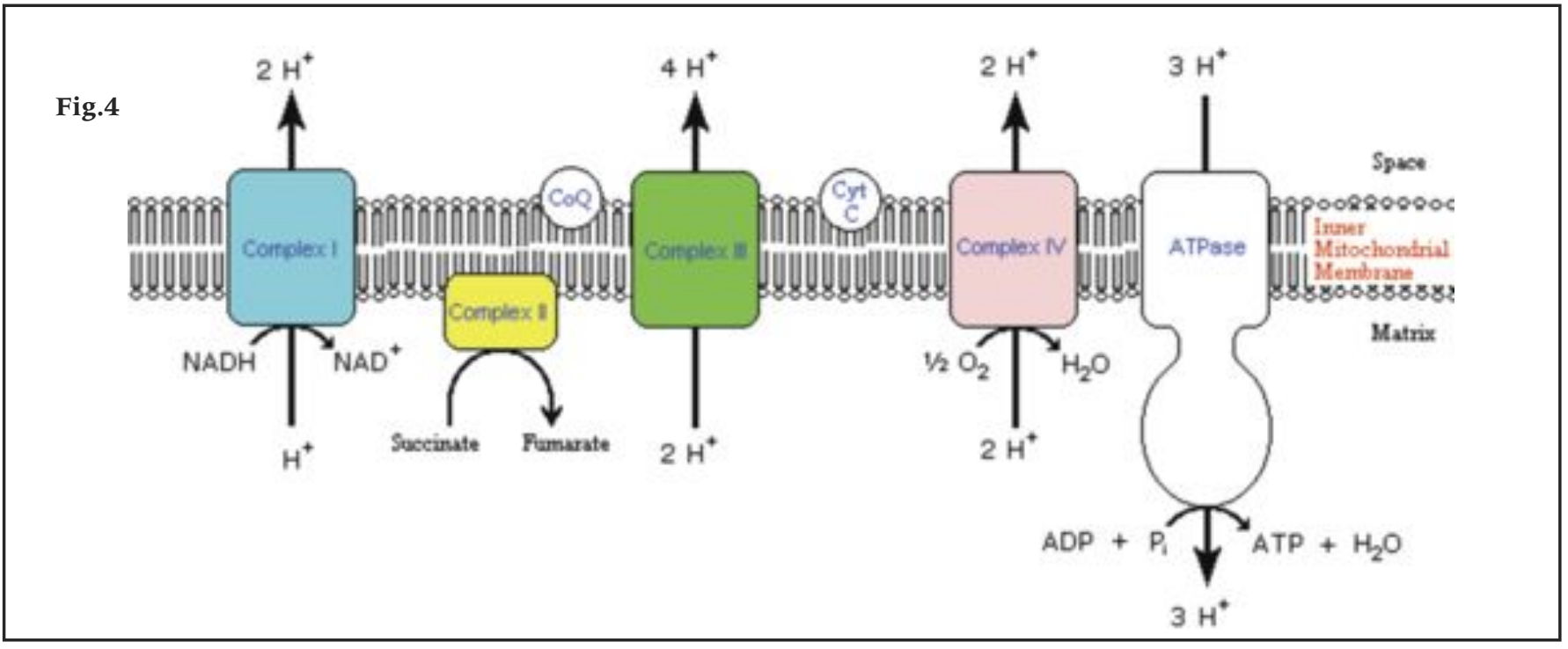


tant and normal mtDNAs in cells, tissues, organs or family lineages. Most pathogenic mtDNA mutations in humans are heteroplasmic, but the heteroplasmic state is not always pathogenic.

4) Different organs rely on mitochondrial energy to different extents. Thus, if oxidative phosphorylation is reduced by genetic insult or environmental stress, it will ultimately fall below the minimum energy threshold necessary for different organs and tissues to function normally (threshold effect) (Fig.6) (7). The mechanisms determining the thresholds for expression are likely to be different for different mtDNA mutations.

Heteroplasmy, threshold effect, site, percentage and inter- and intra-tissue distribution of mtDNA mutations contribute to phenotype, but do not explain the overall clinical heterogeneity, a crucial point in the study of the encephalomyopathies.

Fig.6: Threshold effect

\section{Threshold effect, genetic basis}

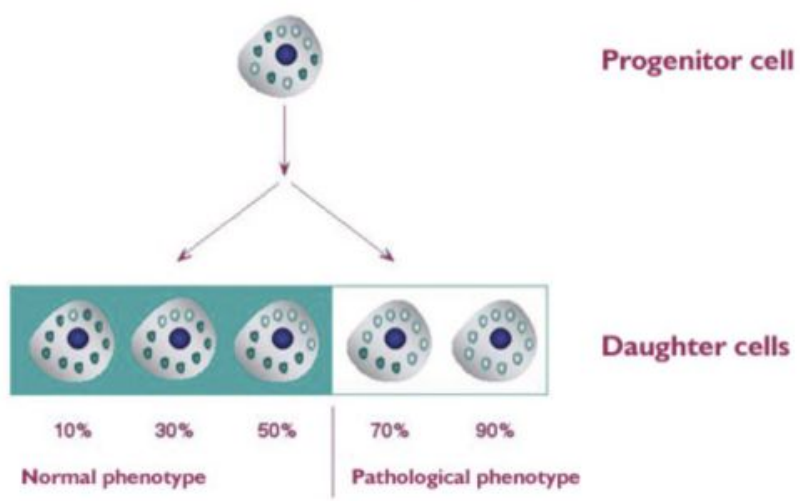

MtDNA mutations are divided into: large-scale rearrangements (sporadic, maternally inherited or mendelian inherited) and point mutations (maternally inherited) (8). About 200 mutations have been described (Mitomap: http://Www.mitomap.org) associated with an extremely heterogeneous spectrum of clinical manifestations.

In many cases, mutations of mtDNA are consistently related to well defined clinical entities: Chronic Progressive External Ophtalmoplegia (CPEO), KearnsSayre Syndrome (KSS), Encephalomyopathy, Lactic Acidosis and Stroke-like Episodes (MELAS), Myoclonic Epilepsy with Ragged-Red Fibers (MERRF), Neuropathy, Ataxia and Retinitis Pigmentosa (NARP) and Leber's Hereditary Optic Neuropathy (LHON). Since overlap syndromes and unusual or aspecific phenotypes are frequent (9), the correlation between genotype and phenotype is not yet clearly understood.

The clinical and biochemical variability of many mtDNA mutations may be caused by different mitochondrial or nuclear "gene backgrounds" or both (10). In turn, deleterious mutations may promote accumula- tion of somatic changes through generation of $\mathrm{OX}$ PHOS-related mutagens. This phenomenon may trigger a positive feedback loop contributing to progression of the mitochondrial dysfunction (11).

\section{MUTATIONS IN NUCLEAR GENES}

Over $90 \%$ of mitochondrial proteins are expressions of nuclear genes. It is therefore surprising that the number of illnesses and syndromes associated with $\mathrm{OX}$ PHOS-related nuclear genes is quite small compared to the number caused by mtDNA mutations. On the other hand, a growing number of hereditary degenerative diseases, especially neurological disorders, have been linked to mutations in genes encoding proteins that enter mitochondria and are more or less directly correlated with OXPHOS.

The proteins encoded by these genes belong to three categories.

1. structural components of the respiratory chain

2. proteins that control OXPHOS or mtDNA metabo-

lism

3. proteins indirectly correlated with OXPHOS

1. Defects in structural components of the respiratory chain

- Complex I defects (Leigh's syndrome,Leukodystrophy, myoclonus)

- Complex II defects (Leigh's Syndrome, Hereditary Paragangliomas)

- defects in the synthesis of coenzyme Q (Ataxia, myoglobinuria, seizures)

2. Defects in factors controlling OXPHOS or mtDNA metabolism

- defects of SURFl (Leigh's Syndrome)

- defects in SCOl (infantile encephalomyopathy)

- defects in SCO2 (infantile cardiomyopathy)

- defects in COX10 (infantile encephalomyopathy)

- defects in COX15 (cardiomyopathy)

- defects in DGUOK (mitochondrial DNA-depletion sindrome, hepatocerebral form)

- defects in TK2 (mitochondrial DNA-depletion sindrome, myopathy)

- defects in POLGl (progressive external ophtalmoplegia, Alpes sindrome)

- defects in BCSI disorder (infantile encephalomyopathy, tubulopathy, hepatopathy)

- defects in ANTI, Twinkle, POLGl (autosomal dominant external ophtalmoplegia)

- Defects of Thymidine Phosphorylase (Mitochondrial Neuro-Gastro-Intestinal Encephalomyopathy, MNGIE)

\section{Disorders of nuclear genes indirectly correlated with OXPHOS}

- defects in OPAl (dominant optic atrophy)

- defects in frataxin (Freidreich's Ataxia)

- defects in paraplegin (hereditary spastic paraplegia)

- defects of Tim 8/9 transporters (X-linked deafness-dystonia syndrome) 


\section{- Mendelian heredity}

\section{DIAGNOSIS OF MITOCHONDRIAL DISEASES}

Mitochondrial disease is caused by a mitochondrial abnormality. Since the mitochondrion is the major energy source in the cell, mitochondrial abnormalities ultimately lead to defects in energy metabolism. There are several structural levels of mitochondrial abnormality, whose expression is different at each level. Each level requires a different detection method, starting with study of inheritance in the family, clinical manifestations in the individual, electrophysiology and imaging techniques at organ level, down to biochemistry, pathology and molecular genetics at tissue, cell and DNA level, respectively.

Until recently, the diagnosis of mitochondrial encephalomyopathies was largely based on altered lactate:pyruvate ratio in serum and on detection of ragged-red fibers (RRF) due to accumulations of structurally abnormal subsarcolemmal mitochondria, that stain red with the Gomori Trichrome stain in muscle biopsy (12). COX stain (cytochrome C oxidase histochemical reaction) also provides useful information.

An important advance towards the identification and characterization of these disorders was the development of methods to measure the activities of individual respiratory enzymes by spectrophotometer. This can be performed in lymphocytes, cultured skin fibroblasts or muscle biopsies (13). Finally, since the identification of mtDNA and nDNA mutations, genetic studies have provided further pathogenetic insights and new diagnostic clues for many of these disorders.

\section{RESULTS}

In Neurogenetics Laboratory, at Department of Neurological and Behavioural Sciences (University of Siena), in the last ten years we have conducted genetic molecular analysis of blood and muscle samples of about 900 patients suspected of diseases with mitochondrial pathogenesis. Molecular diagnoses were obtained for a large number of patients with mitochondrial encephalomyopathies, helping to broaden the spectrum of mutations of the mtDNA molecule and of nuclear genes implicated in the pathogenesis of these diseases. In fact, in our laboratory, we not only analyse the mtDNA molecule but also many nuclear genes, some of which are involved in mitochondrial metabolism; in particular POLG1, OPAl, OPA3 and TP.

We also tried to clarify the correlation between genotype and phenotype and the importance of exogenous factors that contribute to onset of symptoms.

The study produced interesting results that have been the subject of many papers in international journals $(9,14-32)$. Since the amount of work done has been considerable, here we only illustrate one of the many cases recently studied and published by us (32).

\section{CASE REPORT}

A 50-year old woman patient presented with a oneyear history of palpebral ptosis. Family history was positive for myocardial infarction in the paternal line (grandfather/grandmother and uncle). A sister and two daughters of 25 and 12 years were apparently in good health (no muscle biopsies was available). Low stature was a family feature. Psychophysical development was normal. Remote medical history included gynecological disorders, pituitary adenoma and sight problems. Fatigability was ascribed to low serum levels of ferritin. Plasma levels of CPK were 165 U/l (normal value: 70-140 U/1). Neuropsychological assessment was negative. Neurological examination showed left palpebral ptosis with limited eye movements (paralysis of horizontal, mostly right, and vertical conjugate movements, progressive external paralysis). Sporadic episodes of dysphagia and hyposthenia of the muscles of facial expression were reported.

Ophthalmological examination showed left palpebral ptosis, limited eye movement and typical progressive external ophtalmoplegia. Brain NMR with gadolinium contrast showed a faint vascular striation in the right frontal region extending from the anterior horn to the brain surface on the same side, suggesting venous dysplasia. A striking, prevalently cystic formation was observed in the sella, deforming the sellar cavity and displacing the pituitary stalk to the right. Audiometric examination was not normal, with slight auditory loss at high frequencies. ECG and cardiological examination were normal.

\section{Materials ANd Methods}

Morphological analysis of skeletal muscle was conducted as previously described (33). DNA was extracted from skeletal muscle, lymphocytes, mouth and urinary tract epithelium and hair roots using QIAmp DNA Mini kits (Qiagen). MtDNA was analysed for deletions by southern blot using DNA extracted from muscle and PvuII digestion. The following mtDNA fragments, including the 22 genes for mitochondrial tRNA, were amplified by PCR: from nucleotide 503 to 1400,1322 to 2197,2901 to 3797,3701 to 4649,5408 to 6350,7100 to 7900,7750 to 8598,9850 to 10675 , 11880 to 12780,14052 to 14900 and 15451 to 16299 . PCR products were purified directly with QIAquick PCR Purification kits (Qiagen) and analysed with an automatic sequencer.

Mismatch Restriction Fragment Length Polymorphism (RFLP)-PCR analysis was done to assess the degree of heteroplasmy of the various tissues of the patient and to look for the mutation in 110 controls. Since there is no restriction site that can distinguish mutant from normal DNA, we modified an oligonucleotide that created a restriction site for the enzyme HhaI on normal mtDNA. The oligonucleotides used were:

"forward" 12211-12230:

AAGCTCACAAGAACTGCTAA;

"reverse"12351-12316:

AGTGTGCATGGTTATTACTTTTATTTGGAGTTGCG (modified nucleotide underline).

Normal mtDNA was thus cut into two fragments of 105 and 35 base pairs. The fragments were separated by $8 \%$ polyacrylamide gel electrophoresis and visualised 
with UV light after staining with ethidium bromide. The proportion of mutant mtDNA was calculated by densitometry using a Biorad Gel Doc 2000 image analyzer. A lastcycle hot PCR was also performed and the digested products were run on a $8 \%$ polyacrylamide gel. The resulting percentage of the mutation was obtained by a phosphor imager (Molecular analyst, Bio-Rad).

\section{Results}

Muscle biopsy

Histological observation showed a variation in fiber size (the diameter ranged from 16 to $96 \mu \mathrm{m}$ ), $10 \% \mathrm{nu}-$ clear internalization and about $15 \%$ of fibers negative to cytocrome c oxidase staining. Gomori trichrome staining showed 5\% Ragged Red Fibers (RRFs).

\section{Molecular genetic analysis}

Southern blot was negative. Direct sequencing for tRNAs and adjacent regions of all 22 genes showed seven variations of the revised Cambridge reference sequence (rCRS) (34): A750G, A1438G, A1937C, T12254C, G12316A, C14239T and C14766T. These variations were compared with the public "MITO-
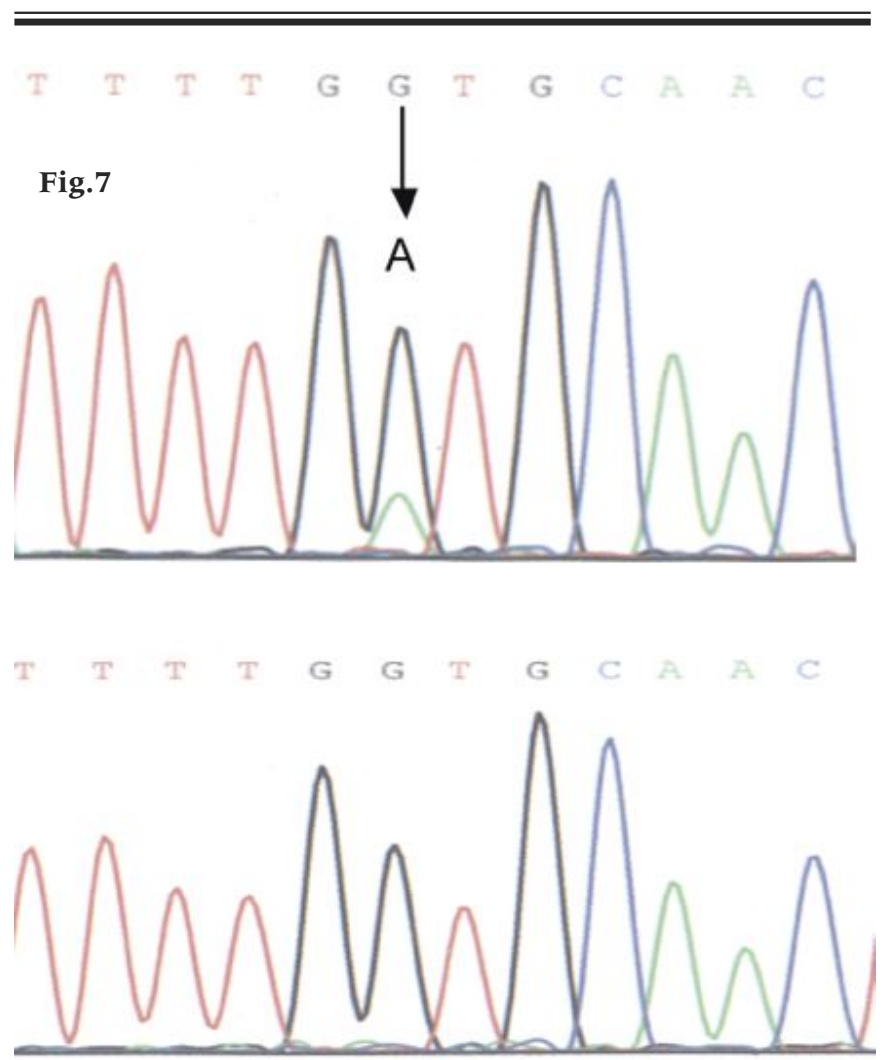

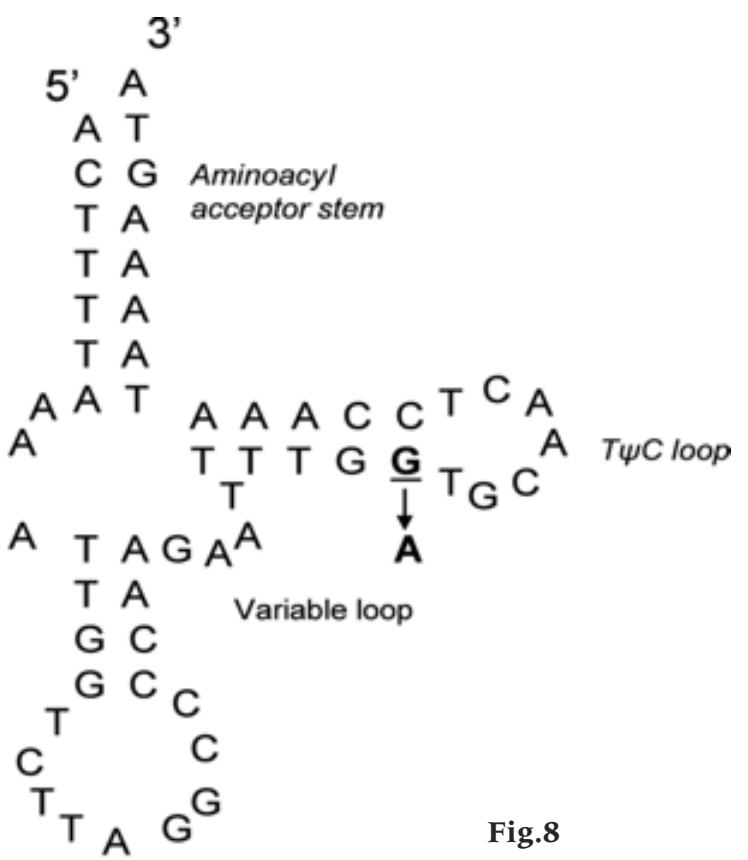

Anticodon loop

Fig.8 (above): Proposed two-dimensional structure of human tRNALeu(CUN) showing the position of the G12316A mutation in the $\mathrm{T} \Psi \mathrm{C}$ branch of the molecule.

Fig.7 (left):

Direct sequencing of mitochondrial tRNALeu(CUN) gene from buccal epithelium (bottom panel) and muscle (top panel). Electropherograms of nucleotide position 12311-12322 showing heteroplasmic G to A transition at position 12316 in muscle mtDNA and its absence from mouth epithelium mtDNA.

Fig.9 (below): Homology of mitochondrial tRNALeu(CUN) among different species: human, gorilla, bovine, mouse, Xenopus laevis and sea urchin. The mutated base in the patient at position 12316 is underlined.

\begin{tabular}{|c|c|c|c|}
\hline & 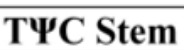 & TЖC Loop & 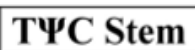 \\
\hline Patient & TTTG묘 & TGCAACT & CCAAA \\
\hline Human & TTTGG & TGCAACT & CCAAA \\
\hline Gorilla & TTTGG & TGCAACT & CCAAA \\
\hline Bovine & ATTGG & TGCAACT & CCAAA \\
\hline Mouse & CTTGG & TGCAAAT & CCAAA \\
\hline Xenopus $l$. & CTTGG & TGCAAAT & CCAAA \\
\hline Sea Urchin & GAGGG & TTCAACT & ССТTC \\
\hline
\end{tabular}


MAP" and "Uppsala mtDB" databases which indicated that they were known polymorphisms, except for A1937C on the rRNA 16S gene and G12316A on the tRNALeu(CUN) gene. The first is in homoplasmic state and affects a region that is relatively exempt from pathogenic mutations. The other mutation in nucleotide position 12316 (Fig.7) is in heteroplasmic state and destroys $\mathrm{G}-\mathrm{C}$ base coupling in the $\mathrm{T} \Psi \mathrm{C}$ branch of the tRNALeu(CUN) molecule (Fig.8). This base pair is highly conserved from sea urchin to human during evolution (Fig.9).

PCR-RFLP anlyses, with and without hot last cycle, and densitometry confirmed that $40 \%$ of muscle, $10 \%$ of urinary epithelium and $3 \%$ of blood mtDNA carried the mutation, which was absent from mtDNA extracted from mouth epithelium and hair roots (Fig. 10) as well as in 110 patients with various encephalopathies.

\section{Discussion}

The clinical phenotype of our patient meets all the criteria for mitochondrial CPEO which is commonly associated with large scale mtDNA deletions. Up to date 17 point mutations in six of the 22 genes for mitochondrial tRNAs have been described in association with CPEO (Mitomap: http://www.mitomap.org) $(35,36)$. In this patient we identified a novel base change in the mitochondrial tRNALeu(CUN)gene. Although we did not sequence the whole mtDNA molecule, G12316A fullfills all pathogenetic criteria for mutations involving genes codifying component of mithocondrial protein synthesis machinery. First of all, the mutation splits a G-C base pair in the $\mathrm{T}^{\mathrm{C}} \mathrm{C}$ branch of the molecule which is highly conserved during the phyloge- netic scale. This change could damage coding of the correct secondary and possibly tertiary structure of tRNA. Secondly, the mutation has never been reported among polymorphisms and was not found in 110 patients with different encephalomyopathies. Third, the mutation is heteroplasmic and detectable only on muscle, urinary tract epithelium and blood (fig 4), with decreasing percentages. Unfortunately we were unable to assess the mutational status in the asymptomatic maternal line relatives (who denied their consent to perform genetic analyses). Finally, this change affects the nucleotide immediately adjacent to the G12315A pathogenic mutation $(37,38)$. The already described G12315A and the G12316A affect the T $\Psi \mathrm{C}$ branch of the molecule in two highly conserved sites. Our patient and the ones described in Fu et al. (37) and Karadimas et al. (38) present with a similar clinical phenotype. It is highly possible that the underlying pathogenetic mechanisms could be similar.

A peculiar feature of our case was the rather low degree of mutant mtDNA in muscle, which we estimated to be $40 \%$ of total mtDNA, compared to four other cases of CPEO, a case of mitochondrial myopathy, one of MELAS and two of dilated cardiomyopathy, associated with point mutations of tRNALeu(CUN), in which the percentage of mutant mtDNA was in the range $59.8 \%$ to $94 \%(37-43)$. This recessive trait is common to most point mutations of mitochondrial tRNAs, the threshold for biochemical and clinical expression of which is usually quite high. However some exception have been reported. Similar data have been described also for the transition A3243G in tRNALeu(UUR) found in about $80 \%$ of MELAS patients, and for other pheno-

Fig.10 (below):

(a) PCR-RFLP analysis with electrophoresis on $8 \%$ polyacrylamide gel. The mutation did not alter natural restriction sites, and a modified primer was used to create a restriction site for the enzyme HhaI, that cuts the normal mtDNA into two fragments of 105 and $35 \mathrm{bp}$ (not visible in the picture), distinguishing mutant and wild-type mtDNAs. The following tissues were studied: buccal epithelium (B); hair root $(\mathrm{H})$; skeletal muscle $(\mathrm{M})$; lymphocytes (L); urinary epithelium (U).
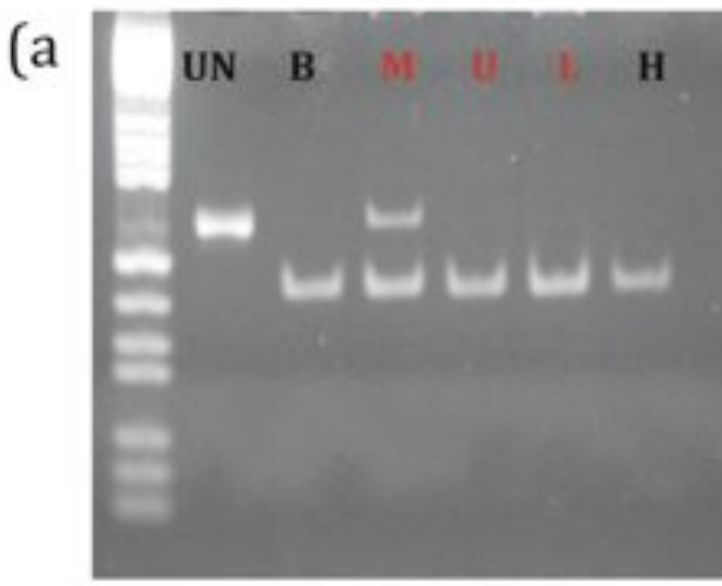

(b) An autoradiogram shows HhaI-digested 32P-labeled PCR products electrophoresed through a $8 \%$ non-denaturing polyacrylamide gel, performed on the tissues of the proband. UN = uncut PCR; C = control DNA. 
types (deafness, diabetes mellitus, KSS, myopathy, encephalopathy without stroke, MERRF/MELAS, LS and CPEO) (44). For this mutation a clear relation between percentage of mutant mtDNA and clinical phenotypes is described. Several studies confirm that higher percentages of mutant mtDNA in muscle are associated with a higher frequency of clinical signs, so that individuals with high percentages in muscle have strokelike episodes at a young age, whereas those with low heteroplasmy develop myopathy and external ophthalmoplegia at a later age (44-47). Two other mutations, tRNALeu(CUN) G12276A and tRNASer(UCN) G7506A, have also been found in CPEO patients with low heteroplasmy: about $18 \%$ for the former (35) and $30 \%$ for the latter (36).

In our patient, the rather low percentage of mutant mtDNA in muscle is in line with the late onset of CPEO and the mild nature of symptoms, suggesting a low threshold for phenotypic expression.

Although we do not have genetic data for the patient's two daughters, they may have inherited the mutation from their mother (if the germinal line is affected) and may develop symptoms at a future time, considering the late onset in their mother and the fact that point mutations of mtDNA may accumulate in time, even in postmitotic muscle (40). Indeed, age-dependent decline in oxidative phosphorylation may add to the deleterious effects of the mutation on respiratory chain function.

In conclusion, we could demonstrate a new mtDNA pathogenic point mutation in a tRNA gene causing CPEO. With this report the total number of tRNALeu(CUN) rises to ten. The clinical and morphological characteristics are in line with the molecular genetic results that show segregation of the mutation prevalently in muscle. Since the clinical phenotype associated with tRNALeu(CUN) point mutations is extremely heterogeneous (Mitomap: http://www. mitomap.org) (35) a peer molecular dissection is uttermost important.

\section{REFERENCES}

1) Wallace DC. Diseases of the mitochondrial DNA. Annu Rev Biochem 1992; 61: 1175-212.

2) Di Mauro S and Bonilla E Mitochondrial encephalomyopathies. In: Rosemberg RN, Prusiner SB, Di Mauro S, Barchi RL, editors. The molecular and genetic basis of neurological disease. 2nd ed. Boston: Butterworth-Heinemann 1997; 201-35.

3) Di Mauro S and Schon EA. Mitochondrial DNA and diseases of the nervous system: the spectrum. Neuroscientist 1998; 4: 53-63.

4) Zeviani M, Bertagnolio B and Uziel G. Neurological presentations of mitochondrial diseases. J Inher Metab Dis 1996; 19: 504-520.

5) Giles RE, Blanc H, Cann HM, Wallace DC. Maternal inheritance of human mitochondrial DNA. Proc Natl Acad Sci USA 1980; 77: 6715-9.

6) Chinnery PF, Howell N, Andrews RM, Turnbull DM. Mitochondrial DNA analysis: polymorphisms and pathogenicity. J Med Genet 1999;36:505-510.

7) Wallace DC, Lott MT. Maternally inherited diseases. In:
Di Mauro S, Wallace DC, eds: Mitochondrial DNA in Human Pathology. New York, NY: Raven Press 1993; 6383.

8) Zeviani M and Antozzi C. Mitochondrial disorders. Mol Hum Reprod 1997; 3(2): 133-48.

9) Fabrizi GM, Cardaioli E, Grieco GS, Cavallaro T, Malandrini A, Manneschi L, Dotti MT, Federico A, Guazzi G. The A to G transition at $n t 3243$ of the mitochondrial tRNALeU(UUR) may cause an MERRF syndrome. J Neurol Neurosurg Psych 1996; 61: 47-51.

10) Marchington DR, Poulton J, Sellar A, Holt IJ et al.?. Do sequence variants in the major non-coding region of the mitochondrial genome influence mitochondrial mutations associated with diseases? Hum Mol Genet 1996;5(4):473479.

11) Kovalenko SA, Tanaka M, Yoneda M, Iakovlev AF, Ozawa T. Accumulation of somatic nucleotide substitutions in mitochondrial DNA associated with the $3243 \mathrm{~A}$ to $\mathrm{G} t R$ NALeu(UUR) mutation in encephalomyopathy and cardiomyopathy. Biochem Biophys Res Commun 1996;222:201-207.

12) Rowland LP, Blake DM, Hirano S et al.. Clinical syndromes associated with ragged-red fibres. Revue Neurologique 1991; 290: 457-465.

13) RustinP, Chretien D, Bourgeron T, et al. Investigation of respiratory chain activity in human heart. Biochem Med Metab Biol 1993; 50: 120-26.

14) Dotti MT, Plewnia K, Cardaioli E, Manneschi L, Rufa A, Alemà G, Federico A. A case of ethambutol-induced optic neuropathy harbouring the primary mitochondrial LHON mutation at $n t$ 11778. J Neurol. 1998 May;245(5):302-3.

15) Federico A, Dotti MT, Cardaioli E, Grieco G, Malandrini A, Manneschi L, Plewnia K, Rufa A, Renieri A, Bruttini M, Perticoni GF. Association in the same patient of autosomal dominant progressive external ophthalmoplegia with multiple mtDNA deletions and $X$-linked ichthyosis: clinical, biochemical, histological, submicroscopic and molecular genetic study. J Submicrosc Cytol Pathol. 1998 Oct;30(4):521-6.

16) Casali C, Fabrizi GM, Santorelli FM, Colazza G, Villanova M, Dotti MT, Cavallaro T, Cardaioli E, Battisti C, Manneschi L, DiGennaro GC, Fortini D, Spadaro M, Morocutti C, Federico A. Mitochondrial G8363A mutation presenting as cerebellar ataxia and lipomas in an Italian family. Neurology. 1999 Mar 23;52(5):1103-4.

17) Cardaioli E, Dotti MT, Hayek G, Zappella M, Federico A. Studies on mitochondrial pathogenesis of Rett syndrome: ultrastructural data from skin and muscle biopsies and mutational analysis at mtDNA nucleotides 10463 and 2835. J Submicrosc Cytol Pathol. 1999 Apr;31(2):301-4.

18) Cardaioli E, Fabrizi GM, Grieco GS, Dotti MT, Federico A. Heteroplasmy of the A3243G transition of mitochondrial tRNA(Leu(UUR)) in a MELAS case and in a 25-weekold miscarried fetus. J Neurol. 2000 Nov;247(11):885-7.

19) Federico A, Rufa A, Battisti C, Bianchi S, Cardaioli E, Da Pozzo P, De Stefano N, Formichi P, Sicurelli F, Dotti MT. Genetic leukoencephalopathies with unknown metabolic pathogenesis. Neurol Sci. 2001 Nov;22 Suppl 2:S108-12. Review.

20) Formichi P, Battisti C, Bianchi S, Cardaioli E, Federico A. Evidence of apoptosis via TUNEL staining in muscle biopsy from patients with mitochondrial encephaloneu- 
romyopathies. J Submicrosc Cytol Pathol. 2003 Jan;35(1):29-34.

21) Gambelli S, Malandrini A, Ginanneschi F, Berti G, Cardaioli E, De Stefano R, Franci M, Salvadori C, Mari F, Bruttini M, Rossi A, Federico A, Renieri A. Mitochondrial abnormalities in genetically assessed oculopharyngeal muscular dystrophy. Eur Neurol. 2004;51(3):144-7. Ерub 2004 Feb 27

22) Dotti MT, De Stefano N, Bianchi S, Malandrini A, Battisti C, Cardaioli E, Federico A. A novel NOTCH3 frameshift deletion and mitochondrial abnormalities in a patient with CADASIL. Arch Neurol. 2004 Jun;61(6):942-5.

23) Da Pozzo P, Cardaioli E, Radi E, Federico A. Sequence analysis of the complete mitochondrial genome in patients with mitochondrial encephaloneuromyopathies lacking the common pathogenic DNA mutations. Biochem Biophys Res Commun. 2004 Nov 5;324(1):360-4.

24) Battisti C, Formichi P, Cardaioli E, Bianchi S, Mangiavacchi $P$, Tripodi SA, Tosi $P$, Federico A. Cell response to oxidative stress induced apoptosis in patients with Leber's hereditary optic neuropathy. J Neurol Neurosurg Psychiatry. $2004 \mathrm{Dec} ; 75(12): 1731-6$.

25) Cardaioli E, Da Pozzo P, Radi E, Dotti MT, Federico A. A novel heteroplasmic tRNA(Leu(CUN)) mtDNA point mutation associated with chronic progressive external ophthalmoplegia. Biochem Biophys Res Commun. $2005 \mathrm{Feb}$ 18;327(3):675-8.

26) Rufa A, Dotti MT, Cardaioli E, Da Pozzo P, Federico A. Leber hereditary optic neuropathy in 2 of 4 siblings with 11778 mtDNA mutation: clinical variability or effect of toxic environmental exposure? Eur Neurol. 2005;53(1):32-4.

27) Cardaioli E, Gallus GN, Da Pozzo P, Rufa A, Franceschini R, Motolese E, Caporossi A, Dotti MT, Federico A. A novel mutation producing premature termination codon at the OPA1 gene causes autosomal dominant optic atrophy. J Neurol. 2006 May;253(5):672-3.

28) Cardaioli E, Da Pozzo P, Cerase A, Sicurelli F, Malandrini A, De Stefano N, Stromillo ML, Battisti C, Dotti MT, Federico A. Rapidly progressive neurodegeneration in a case with the 7472insC mutation and the A7472C polymorphism in the mtDNA tRNA ser(UCN) gene. Neuromuscul Disord. 2006 Jan;16(1):26-31.

29) Petruzzella V, Tessa A, Torraco A, Fattori F, Dotti MT, Bruno C, Cardaioli E, Papa S, Federico A, Santorelli FM. The NDUFB1 1 gene is not a modifier in Leber hereditary optic neuropathy. Biochem Biophys Res Commun. 2007 Mar 30;355(1):181-7.

30) Cardaioli E, Da Pozzo P, Gallus GN, Franceschini $R$, Rufa A, Dotti MT, Caporossi A, Federico A. Leber's hereditary optic neuropathy associated with cocaine, ecstasy and telithromycin consumption. J Neurol. 2007 Feb;254(2):255-6. Epub 2007 Mar 2.

31) Cardaioli E, Da Pozzo P, Gallus GN, Malandrini A, Gambelli S, Gaudiano C, Malfatti E, Viscomi C, Zicari E, Berti G, Serni G, Dotti MT, Federico A. A novel heteroplasmic tRNA(Ser(UCN)) mtDNA point mutation associated with progressive external ophthalmoplegia and hearing loss.Neuromuscul Disord. 2007 Oct;17(9-10):681-3.

32) Cardaioli E, Da Pozzo P, Malfatti E, Gallus GN, Rubegni A, Malandrini A, Gaudiano C, Guidi L, Serni G, Berti G, Dotti MT e Federico A. Chronic Progressive External Ophthalmoplegia: a new heteroplasmic tRNALeu(CUN) mutation of mitochondrial DNA. J Neurol
Sci. 272(1-2):106; 2008.

33) Zeviani M, Tiranti V, Piantadosi C. Mitochondrial disorders. Medicine (Baltimore) 1998;77(1):59-72.

34) Andrews RM, Kubacka I, Chinnery PF, Lightowlers RN, Turnbull DM, Howell N. Reanalysis and revision of the Cambridge reference sequence for human mitochondrial DNA.

Nat Genet 1999;23(2):147.

35) Cardaioli E, Da Pozzo P, Radi E, Dotti MT, Federico A. A novel heteroplasmic tRNALeu(CUN) mtDNA point mutation associated with chronic progressive external ophthalmoplegia. Biochem Biophys Res Commun 2005;327(3):675-8.

36) Cardaioli E, Da Pozzo P, Gallus GN et al. A novel heteroplasmic tRNA(Ser(UCN)) mtDNA point mutation associated with progressive external ophthalmoplegia and hearing loss. Neuromuscul Disord. 2007;17(9-10):681-3

37) Fu K, Hartlen R, Johns T, Genge A, Karpati G, Shoubridge EA. A novel heteroplasmic tRNALeu(CUN) mtDNA point mutation in a sporadic patient with mitochondrial encephalomyopathy segregates rapidly in skeletal muscle and suggests an approach to therapy. Hum Mol Genet 1996;5(11):1835-1840.

38) Karadimas CL, Salviati L, Sacconi S et al. Mitochondrial myopathy and ophtalmoplegia ina sporadic patient with the G12315A mutation in mitochondrial DNA. Neuromuscul Disord 2002;12(9):865-868.

39) Hattori $Y$, Goto $Y$, Sakuta R, Nonaka I, Mizuno Y, Horai S. Point mutations in mitochondrial tRNA genes: sequence analysis of chronic progressive external ophtalmoplegia (CPEO). J Neurol Sci1994;125(1):50-55.

40) Weber $K$, Wilson JN, Taylor L et al. A new mtDNA mutation showing accumulation with time and restriction to skeletal muscle. Am J Hum Genet 1997;608(2):373-380.

41) Tessa A, Vilarinho L, Casali C, Santorelli FM. MtDNArelated idiopathic dilated cardiomyopathy. Eur J Hum Genet 1999;7(8):847-848.

42) Grasso M, Diegoli M, Brega A, Campana C, Tavazzi L, Arbustini E. The mitochondrial DNA mutation T12297C affects a highly conserved nucleotide of tRNALeu(CUN) and is associated with dilated cardiomyopathy. Eur J Hum Genet 2001;9(4):311-5.

43) Pulkes T, Liolitsa D, Nelson IP, Hanna MG. Classical mitochondrial phenotypes without mtDNA mutations: the possible role of nuclear genes. Neurology 2003;61(8):11441147.

44) Koga Y, Akita Y, Takane N, Sato Y, Kato H. Heterogeneous presentation in A3243G mutation in the mitochondrial tRNALeu(UUR) gene. Arch Dis Child 2000;82(5):407-411.

45) Chinnery PF, Howell N, Lightowlers RN, Turnbull DM. Molecular pathology of MELAS and MERRF. The relationship between mutation load and clinical phenotypes. Brain 1997;120(Pt10):1713-1721.

46) Laforet $P$, Ziegler F, Sternberg $D$ et al. "MELAS" (A3243G) mutation of mitochondrial DNA: a study of the relationships between the clinical phenotype in 19 patients and morphological and molecular data. (in French). Rev Neurol (Paris) 2000;156(12):1136-1147.

47) Chinnery PF, Taylor DJ, Brown DT, Manners D, Styles $P$, Lodi R. Very low levels of the mtDNA A3243G mutation associated with mitochondrial dysfunction in vivo. Ann Neurol 2000;47(3):381-384. 